\title{
Primary chemoradiation as definitive treatment for unresectable cancer of the trachea
}

\author{
Gregory MM Videtic MD CM FRCPC ${ }^{1}$, Carolyn Campbell MD FRCPC ${ }^{2}$, Mark D Vincent MD FRCPC 3
}

\begin{abstract}
GMM Videtic, C Campbell, MD Vincent. Primary chemoradiation as definitive treatment for unresectable cancer of the trachea. Can Respir J 2003;10(3):143-144.

A 64-year-old man was diagnosed with unresectable cancer of the trachea. He was treated definitively with a novel chemoradiation regimen. Cisplatin-based chemotherapy (ChT) was given for two cycles as induction, followed by concurrent administration of this ChT with external beam radiotherapy (RT) (total dose 60 Gy). An unexpected partial tumour response was noted after the induction of ChT alone. Six weeks after finishing ChT/RT, complete response of the lesion was noted on computed tomography imaging. Two years later, the patient was free of disease. Primary chemoradiation appears to be effective in managing locally advanced tracheal cancer.
\end{abstract}

Key Words: Cancer of the trachea; Chemoradiation; Unresectable

\section{Radio chimiothérapie primaire en traitement définitif du cancer non résécable de la trachée}

\begin{abstract}
Un cancer non résécable de la trachée a été diagnostiqué chez un homme âgé de 64 ans. Le patient a reçu un traitement définitif par une nouvelle méthode de radio chimiothérapie. Deux cycles de chimiothérapie à base de cisplatine ont été administrés à titre de traitement d'induction, suivis de l'administration de la même chimiothérapie en même temps qu'une radiothérapie externe (dose totale de $60 \mathrm{~Gy}$ ). Une réponse tumorale partielle inattendue a été constatée après la chimiothérapie d'induction seule. Six semaines après la fin de la chimiothérapie-radiothérapie, une réponse complète de la lésion a été observée à la tomodensitométrie. Deux ans plus tard, le patient était exempt de la maladie. La radio chimiothérapie primaire semble être efficace dans le traitement du cancer de la trachée localement avancé.
\end{abstract}

$\mathrm{T}$ he rarity of malignant tracheal tumours presents challenges in defining their optimal management (1). Surgery has historically been considered the treatment of choice $(1,2)$. External beam radiotherapy (RT) has been principally employed in the postoperative setting, as primary therapy for unresectable lesions or for palliation $(1,3)$. The role of chemotherapy (ChT) has been ill defined (1). In light of the trend of treating unresectable lung malignancies with concurrent chemoradiation $(4,5)$, we now report the case of a 64-year-old man with locally advanced cancer of the trachea who was treated with a novel chemoradiation regimen.

\section{CASE PRESENTATION}

A 64-year-old male patient with an 80 pack-year smoking history developed a severe cough in 1999, which worsened over the course of one year. He was treated presumptively for asthma, gastroesophageal reflux and postnasal drip with bronchodilators, antacids and steroids, but obtained no relief. Chest radiographs were unremarkable. Pulmonary function tests showed mixed airflow obstruction. The cough became intractable and he developed stridor.

Computed tomography (CT) of the thorax showed narrowing of the trachea above the carina by a $4 \mathrm{~cm}$ intraluminal mass that also invaded into the superior vena cava and was associat- ed with a large subcarinal lymph node (Figure 1). The chest and upper abdomen were otherwise clear. Bronchoscopy revealed a circumferential tracheal lesion lying a few centime-

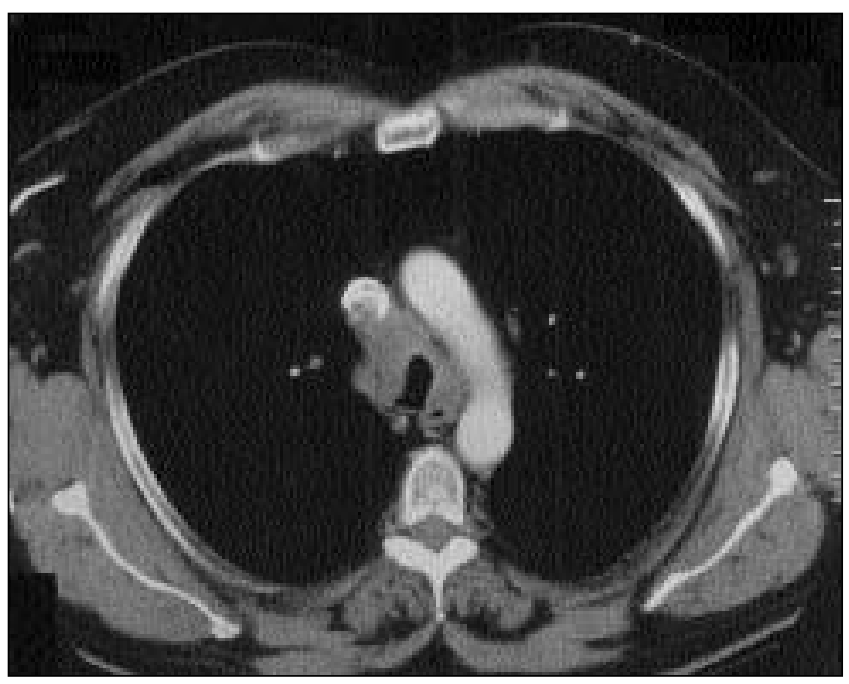

Figure 1) Chest computed tomography image showing a locally advanced tracheal tumour before treatment

${ }^{1}$ Department of Radiation Oncology, Dana-Farber Cancer Institute, Harvard Medical School, Boston, Massachusetts, USA; ${ }^{2}$ Department of Medical Oncology, Grand River Cancer Centre, Kitchener, Ontario; ${ }^{3}$ Department of Medical Oncology, London Regional Cancer Centre, London, Ontario

Correspondence: Dr Gregory Videtic, Radiation Oncology /T28, Cleveland Clinic Foundation, 9500 Euclid Avenue, Cleveland, Ohio 44195, USA. Telephone 216-444-5576, fax 216-445-7595, e-mail videtig@ccf.org 


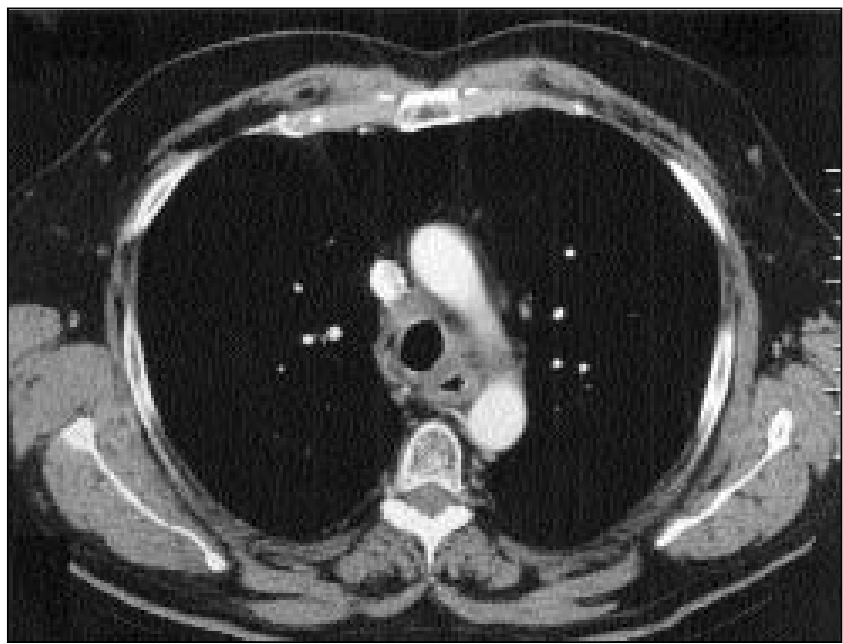

Figure 2) Chest computed tomography image demonstrating complete response of a locally advanced tracheal tumour to concurrent chemoradiation

ters above the carina with a slip of tumour extending into the right mainstem bronchus. A biopsy showed squamous cell carcinoma. Staging investigations, including CT of the head, bone scan and abdominal ultrasound, were negative for metastases. After review at the London Regional Cancer Centre, London, Ontario, a novel regimen of induction ChT followed by concurrent chemoradiation was offered to the patient when a surgical oncologist judged the tumour to be unresectable.

Intravenous ChT consisted of cisplatin $\left(20 \mathrm{mg} / \mathrm{m}^{2}\right.$, day 1 to 5), etoposide ( $50 \mathrm{mg} / \mathrm{m}^{2}$, day 1 to 5), leucovorin $\left(20 \mathrm{mg} / \mathrm{m}^{2}\right.$, day 1 to 5 ), and 5 -fluorouracil [5-FU] ( $500 \mathrm{mg} / \mathrm{m}^{2}$ by continuous infusion, day 1 to 5) (PELF), given every 28 days. Two cycles of PELF were given as induction followed by two concurrent cycles with RT. External beam RT consisted of 60 Gy in 30 fractions delivered by $18 \mathrm{MV}$ photons using a three-field set-up (generated by a three-dimensional CT planning system). CT images at the time of three-dimensional planning revealed an unexpected partial response of the tumour to the induction ChT.

During treatment, 5 -FU dosing was reduced by $10 \%$ due to severe diarrhea. The patient developed a deep vein thrombosis of the left leg that was treated with subcutaneous injections of low molecular weight heparin followed by an oral anticoagulant. The patient developed expected, but mild, esophagitis and reported signs of ChT-induced peripheral neuropathy. Three weeks after finishing all treatment, he complained of increasing odynophagia and dysphagia, and was found, on endoscopy, to have a $2.5 \mathrm{~cm}$ ulcer of the upper thoracic esophagus (within the RT field). Omeprazole, morphine elixir, viscous lidocaine and nystatin suspension were initiated, with relief of symptoms.

Thoracic CT one month after treatment assessed the tumour response. No definite mass in the mediastinum or trachea was identified (Figure 2). Postradiation changes around the trachea and esophagus were noted. The patient was followed with regular clinical examinations and imaging for two years, and continued to do well, with no evidence of disease and no severe late complications from treatment.

\section{DISCUSSION}

Although the conventional treatment for unresectable carcinoma of the trachea is primary RT (2), outcomes are generally believed to be modest at best, as seen in the wide variation of reported survival and local control rates $(1,2)$. RT doses 60 Gy and above appear to provide greater tumour control but may be associated with increased complication rates (2). The current approach for other locally advanced tumours of the aerodigestive tract favours the use of combined modality ChT and RT over RT alone, as demonstrated, for example, in results from randomized trials of unresectable, nonsmall cell lung cancer $(4,5)$. In particular, recent studies show trends in improved survival and local control with the delivery of ChT in a concomitant, as opposed to a sequential, fashion with RT. Evolving strategies in combined modality therapy now include the addition of an induction phase to the concurrent regimen in the hope of improving distant, as well as local, control (6). This prompted the recommendation for the two-phase approach used in the present case.

In the absence of defined ChT drugs with significant activity against tracheal carcinoma (1), the PELF regimen was developed with agents that had activity against squamous cell cancer of the aerodigestive tract and included a platinum compound (5); that had been used previously in concurrent chemoradiation lung trials $(4,5)$; that had broad noncross reacting coverage (5); and that had potential radiosensitization effects (eg, 5-FU infusion) (5). Likewise, a total RT dose of $60 \mathrm{~Gy}$ was selected based on its documented tolerability in tracheal cancer (2) and in keeping with reported doses in randomized thoracic chemoradiation trials (4).

The present case is remarkable for the partial response elicited with ChT alone followed by the early complete response seen on post-treatment imaging. The side effect profile observed was in keeping with expected toxicities from ChT and RT used in treating aerodigestive tract lesions and was easily managed. These encouraging findings suggest that further study of combined modality regimens for unresectable tracheal malignancies is warranted. Of interest is that the only published report describing the use of chemoradiation alone in the treatment of an unresectable tracheal tumour involved a case of an extremely rare adenoid cystic carcinoma (7).

\section{REFERENCES}

1. Meyers BF, Mathisen DJ. Management of tracheal neoplasms. Oncologist 1997;2:245-53.

2. Compeau CG, Keshavjee S. Management of tracheal neoplasms. Oncologist 1996;1:347-53.

3. Chow DC, Komaki R, Libshitz HI, et al. Treatment of primary neoplasms of the trachea - The role of radiation therapy. Cancer 1993;71:2946-52.

4. Mehta MP. The contemporary role of radiation therapy in the management of lung cancer. Surg Clin Oncol N Am 2000;9:539-61

5. Hansen HH, Roerth M. Lung cancer. In: Pinedo HM, Longo DL, Chabner BA, eds. Cancer Chemotherapy and Biological Response Modifiers, Annual 18. New York: Elsevier Science, 1999:336-56.

6. Socinski MA, Rosenman JG, Halle J, et al. Dose-escalating conformal thoracic radiation therapy with induction and concurrent carboplatin/paclitaxel in unresectable stage IIIA/B nonsmall cell lung carcinoma. Cancer 2001;92:1213-23.

7. Sasiaja M, Funa N, Kamata M, Furutani K, Matsumoto A, Kodaira T. Unresectable adenoid cystic carcinoma of the trachea treated with chemoradiotherapy. Clin Oncol 2000;2:272. 


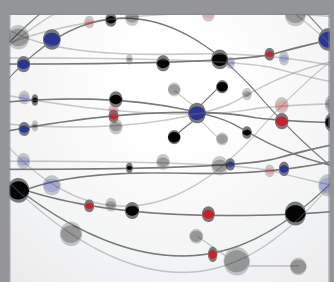

The Scientific World Journal
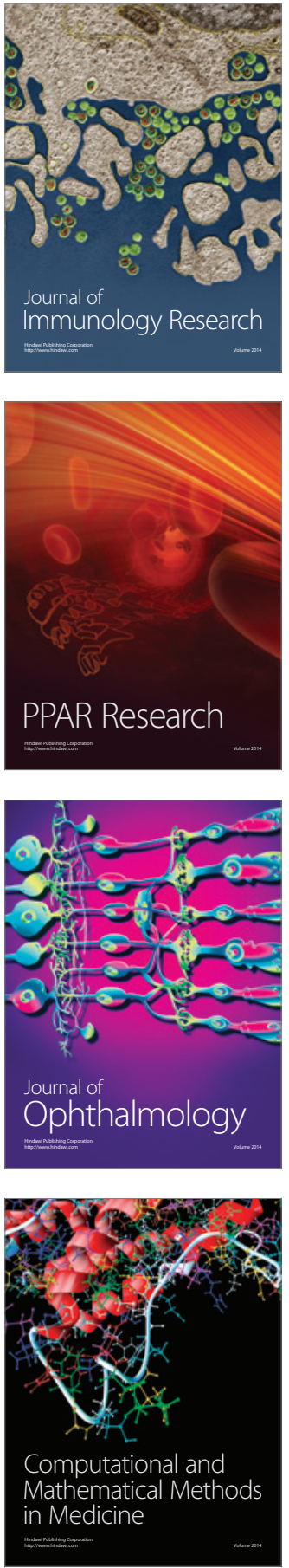

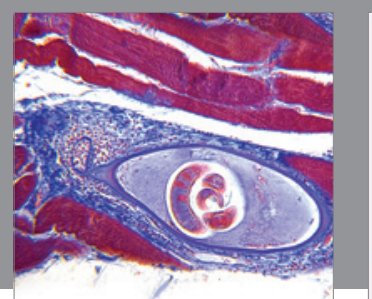

Gastroenterology Research and Practice

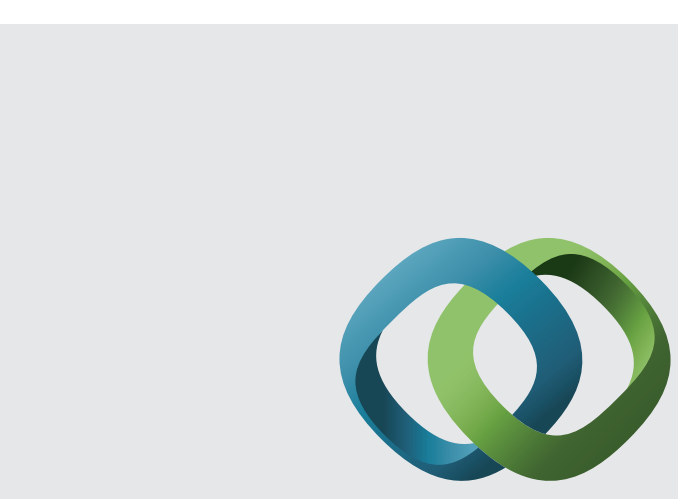

\section{Hindawi}

Submit your manuscripts at

http://www.hindawi.com
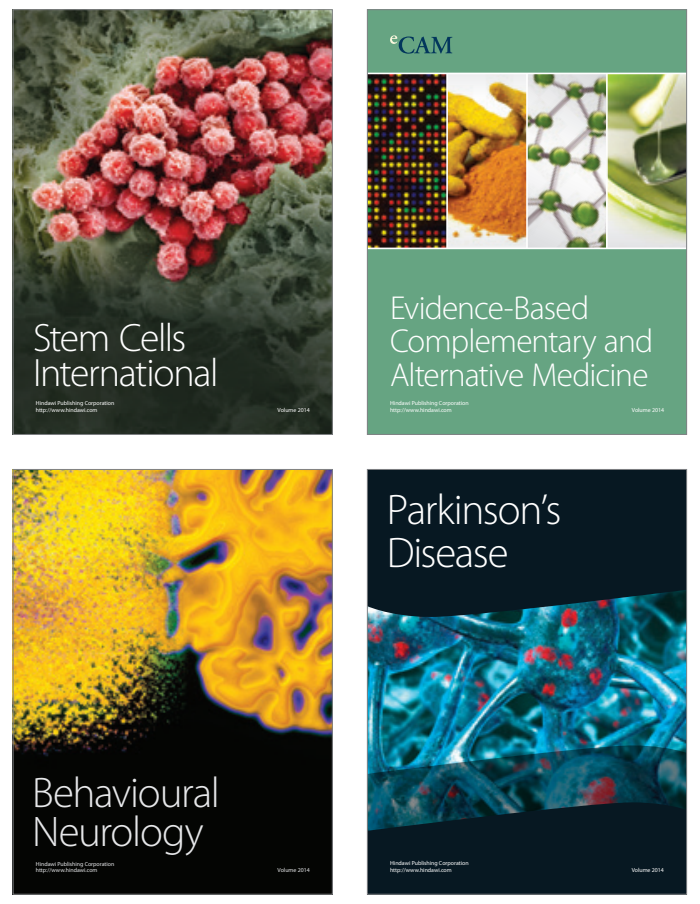
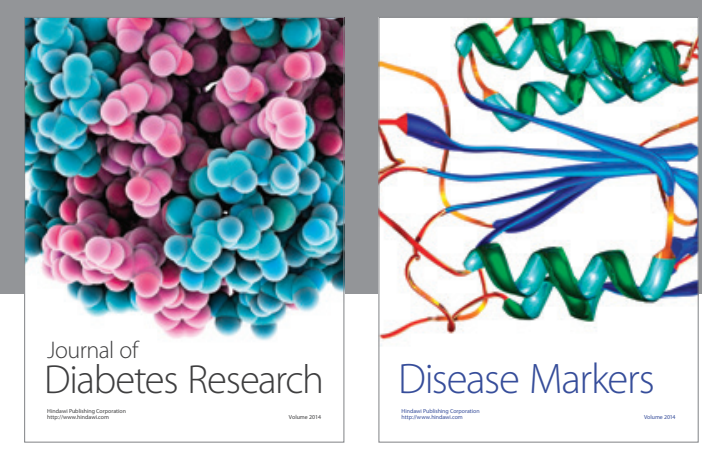

Disease Markers
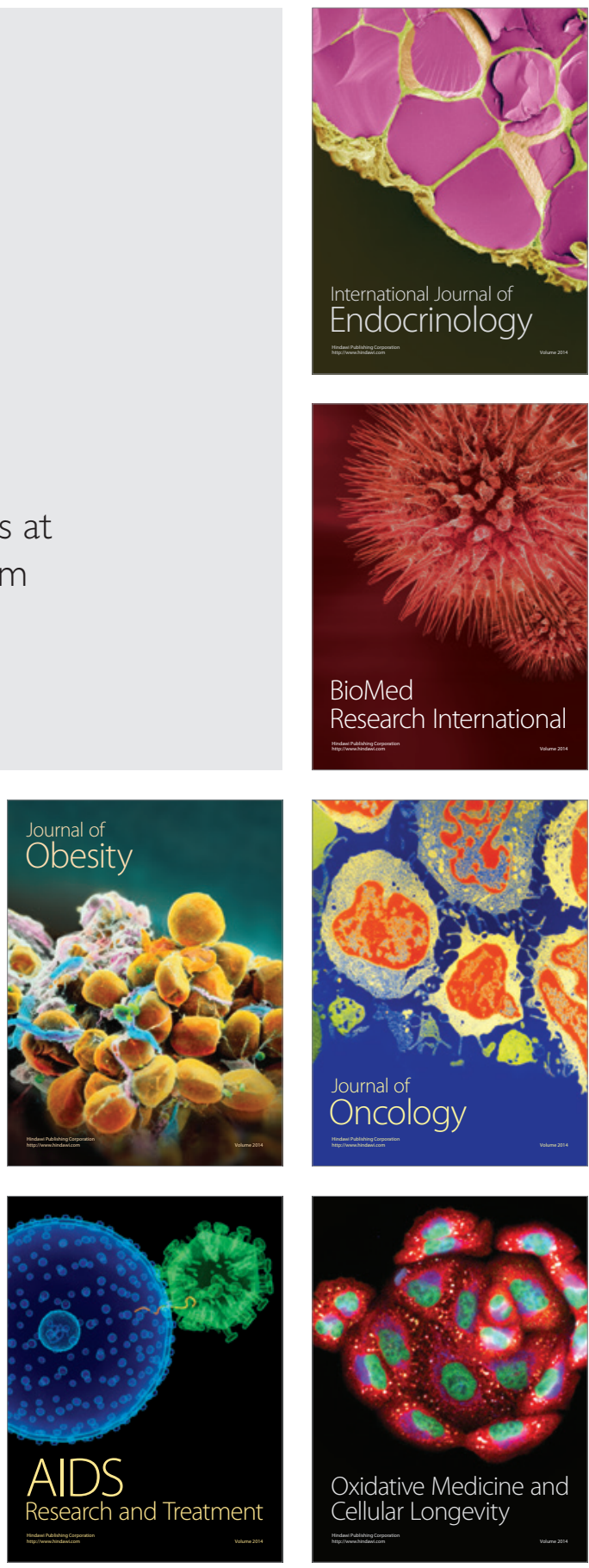